\title{
SYNTHESIS, CHARACTERIZATION, AND EVALUATION OF ANTIFUNGAL PROPERTIES OF SUBSTITUTED BENZIMIDAZOLE ANALOG
}

\author{
VIJEY AANANDHI M*, ANBHULE SACHIN J \\ Department of Pharmaceutical Chemistry and Analysis, School of Pharmaceutical Sciences, Vels Institute of Science, Technology and \\ Advanced Studies, Chennai, Tamil Nadu, India. Email: hodpchemistry@velsuniv.ac.in
}

Received: 10 October 2018, Revised and Accepted: 11 December 2018

\section{ABSTRACT}

Objective: The aim of the present study is to synthesize novel benzimidazole derivatives as potent antifungal agents.

Methods: 2-chloromethyl-1H-benzimidazole has been synthesized by refluxing o-phenylenediamine with chloroacetic acid in the presence of $5 \mathrm{~N}$ HCL. Further, N-substituted benzimidazole derivatives containing various heteroamines and aromatic compounds were synthesized. These, finally, prepared derivatives were kept for in vitro antifungal property.

Results: A novel series of antifungal agents, containing benzimidazole nucleus as a basic skeleton, has been synthesized

Conclusion: The synthesized novel benzimidazole derivatives exhibit moderate activity (VMSA 1, 2, 8), some compounds showed significant activity (VMSA 6, 9, and 10), and compound VMSA 4 and 5 exhibits maximum activity.

Keywords: Benzimidazole, In vitro, Significant, Antifungal activity, Aromatic.

(C) 2018 The Authors. Published by Innovare Academic Sciences Pvt Ltd. This is an open access article under the CC BY license (http://creativecommons. org/licenses/by/4. 0/) DOI: http://dx.doi.org/10.22159/ajpcr.2018.v11s4.31677

\section{INTRODUCTION}

The fungi are more gradually developed form of organism when compared to unicellular organism such as bacteria, viruses, and prions. The fungi are classified as eukaryotes which have nuclear membrane that surrounds the nucleus. The fungi have complex structural features due to genetic and morphological complexity $[1,2]$

It is observed that, among all the different microbes available, fungi have a tremendous impact on the immunocompromised patients and which is emerged as a major infection [3].

There has been significant progress in developing and implementing strategies for the development of new antifungal agents. One strategy for antifungal drug development besides the classical screening of many classes of synthetic or natural products against a variety of fungi involves the use of the molecular biological revolution. It is now possible to identify molecular targets that are essential for fungal virulence. The identification of unique genes and their signaling network, important to the path biology of fungi, could translate into their use as molecular targets for drug development. There are, now, a series of molecular techniques to identify gene expression(s) under certain conditions, and the field of molecular pathogenesis has matured to the point that validation for these potential "virulence" targets can be achieved [4-7]

Furthermore, area of cell biology is now being focused, within pathogenic fungi, and uses all the molecular and biochemical tools and understanding to dissect it, and thereby, attempt was taken for selecting specific fungicidal objects having different selectivity with mammalian cells. Many potential objects for antifungal drug development have been recognized [8].

These can vary from the azoles which inhibit cyt.P450-dependent endoplasmic reticulum where ergosterol gets biosynthesized. A certain antifungal agent such as Amphotericin B which attach to ergosterol inducing conformational change with formation of ionic pores. Echinocandins inhibit $1,3-\beta-D$ glucan synthesis induced by $\beta-1,3$ glucan synthesis $[9,10]$.
Although currently therapeutic choice for the use of invasive fungal infection has some limits, most of antifungal compounds are not too specific due to resistance development, toxicity of host, and side effects which are undesirable [11]. The azole category of antifungal drugs has different agents which are under various clinical phases. These azole category drugs inhibit membrane-bound enzyme. The selected objects of azoles are cyt.P450 and lanosterol-14 demethylase [12]. Ergosterol biosynthesis was inhibited due to azoles which directly reduce the fungal growth by the binding of active sites with azoles [13]. The biosynthesis of plant phytosterol, animal cholesterol, and fungal sterol create an intermediate step due to hemoprotein [14]

As azoles and their derivatives are the most important class of the aromatic heterocyclic compounds exhibiting a wide range of biological applications, especially as active moieties in first-, second-, and thirdgeneration azoles which act as antifungal agents such as miconazole, econazole, fluconazole, itraconazole, and voriconazole, we were now in position for exploring further possibilities in azoles compounds $[15,16]$.

Structural modification has shown that the azole compounds also exhibit properties such as antibacterial [17], anticonvulsant $[18,19]$, anticancer [20,21], anti-inflammatory [22,23], antimalarial [24], antineoplastic [25], insecticidal, and herbicidal [26].

\section{METHODS}

1. The chemicals necessary for the study were purchased from Merck and they were purified before use.

2. Campbell melting point apparatus was used for determining melting point of synthesized compounds.

3. The thin-layer chromatographic method was used where Silica Gel-G was selected for the preparation of thin-layer chromatography (TLC) plates.

4. TLC plates gets visualized under iodine vapors or observed below UV light.

5. "SHIMADZU 3100" and "JASCO 530V" were used for determining infrared spectra. $\mathrm{CDCl}_{3} /$ dimethyl sulfoxide (DMSO) was used for 
determining ${ }^{1} \mathrm{H}$-nuclear magnetic resonance spectra where standard selected is tetramethylsilane (Schemes 1 and 2).

\section{Antifungal property of synthesized compound}

The antifungal activity of the synthesized compounds was carried out using well-plate method, and minimum inhibitory concentrations (MIC) values were calculated as $\mu \mathrm{g} / \mathrm{ml}$. The compounds were tested against Candida albicans, Penicillium notatum, Aspergillus niger, and Aspergillus fumigatus.

Stock solutions of the synthesized derivatives were prepared in DMSO. Dilution series using sterile water were prepared from $12.5 \mu \mathrm{g} / \mathrm{ml}$ to $100 \mu \mathrm{g} / \mathrm{ml}$ in microtest tubes. Suspension of test organism was freshly prepared in $1 \mathrm{ml}$ of sterile normal saline solution and was standardized spectrophotometrically to $10^{7} \mathrm{CFU} / \mathrm{ml}$.

\section{RESULTS AND DISCUSSION}

A novel series of antifungal agents, containing benzimidazole nucleus as a basic skeleton, has been synthesized. The antifungal testing of synthesized compounds was carried out using A. niger, C. albicans, A. fumigatus, and $P$. notatum as a strain.
Among synthesized compounds, VMSA 1, 2, and 8 (MIC $=100 \mu \mathrm{g} / \mathrm{mL}$ ) and 3 and 7 (MIC=50 $\mu \mathrm{g} / \mathrm{mL}$ ) exhibit significant activity against C. albicans, whereas compounds VMSA 6, 9, and 10 (MIC=25 $\mu \mathrm{g}$ / $\mathrm{mL}$ ) showed significant activity. VMSA 4 and 5 show greater activity (MIC $=12.5 \mu \mathrm{g} / \mathrm{mL}$ ) compared with MIC of the ketoconazole (Tables 1 and 2).

\section{CONCLUSION}

From the literature survey, it was found that there has been a lot of research going in the field of novel antifungal drug development. It was found that many antifungal agents contain benzimidazole moieties in their structure. Therefore, benzimidazole was selected for the development of new chemical entities as potential antifungal agents.

Ten benzimidazole derivatives containing heteroamines and aromatic compounds were prepared. The prepared compounds were confirmed by different spectroscopic and chromatographic techniques.

Well plate method was used for testing in vitro antifungal activity of ten synthesized compounds. These activities were observed in agar culture plates in the form of zone of inhibition which was recorded in

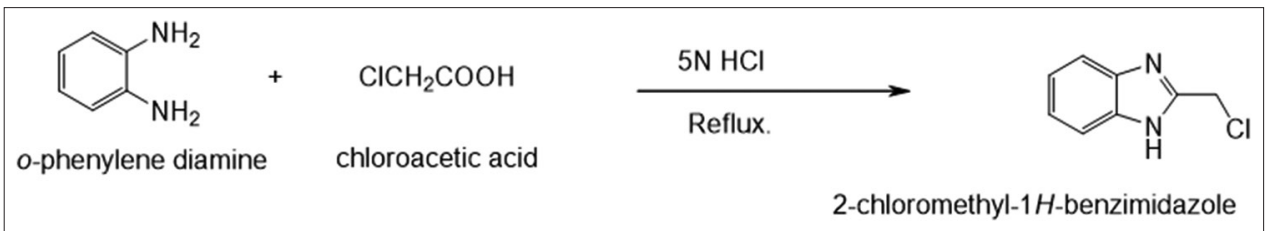

Scheme 1: Preparation of chloromethyl substituted benzimidazole compound

2-chloromethyl-1 $\mathrm{H}$-benzimidazole

Scheme 2: Synthesis of 2-chloromethyl-1 $H$-benzimidazole derivatives

Table 1: Physicochemical study of 2-chloromethyl-1H-benzimidazole derivatives

\begin{tabular}{llllll}
\hline Code & Molecular formula & \% Yield & Molecular pressure ( ${ }^{\circ} \mathbf{C}$ ) & Rf value \\
\hline VMSA1 & $\mathrm{C}_{15} \mathrm{H}_{13} \mathrm{~N}_{3} \mathrm{O}_{2}$ & 70 & \\
\end{tabular}


Table 1: (Continued)

\begin{tabular}{|c|c|c|c|c|c|}
\hline Code & $\mathbf{R}$ & Molecular formula & $\%$ Yield & Molecular pressure $\left({ }^{\circ} \mathrm{C}\right)$ & Rf value \\
\hline VMSA3 & & $\mathrm{C}_{14} \mathrm{H}_{12} \mathrm{~N}_{3} \mathrm{Cl}$ & 53 & $155-157$ & 0.58 \\
\hline VMSA4 & & $\mathrm{C}_{11} \mathrm{H}_{9} \mathrm{~N}_{5} \mathrm{O}_{2}$ & 65 & $118-120$ & 0.62 \\
\hline VMSA5 & & $\mathrm{C}_{10} \mathrm{H}_{10} \mathrm{~N}_{6}$ & 61 & $158-160$ & 0.68 \\
\hline VMSA6 & & $\mathrm{C}_{15} \mathrm{H}_{13} \mathrm{~N}_{3} \mathrm{O}_{2}$ & 52 & $163-165$ & 0.58 \\
\hline VMSA7 & & $\mathrm{C}_{14} \mathrm{H}_{12} \mathrm{~N}_{3} \mathrm{Cl}$ & 56 & $98-100$ & 0.62 \\
\hline VMSA8 & & $\mathrm{C}_{15} \mathrm{H}_{15} \mathrm{~N}_{3}$ & 69 & $82-84$ & 0.55 \\
\hline VMSA9 & & $\mathrm{C}_{15} \mathrm{H}_{12} \mathrm{ClN}_{3} \mathrm{O}_{2}$ & 53 & $180-182$ & 0.70 \\
\hline VMSA10 & & $\mathrm{C}_{15} \mathrm{H}_{15} \mathrm{~N}_{3}$ & 47 & $158-160$ & 0.67 \\
\hline
\end{tabular}

centimeters. Compounds VMSA 1, 2, and 8 and VMSA 3 and 7 showed intense activity against $C$. albicans, whereas compounds VMSA 6, 9, and 10 exhibit greater activity. VMSA 4 and 5 exhibit maximum activities with MIC compared to that of the ketoconazole.

\section{ACKNOWLEDGMENT}

The authors are thankful to the Institute of Science, Technology and Advanced Studies and its management for providing research facilities and encouragement. We have pleasure to express our sincere thanks to 
Table 2: In vitro antifungal activity of benzimidazole derivatives (MIC data for prepared derivatives)

\begin{tabular}{lll}
\hline S. No. & Mol. Code. & MIC $(\boldsymbol{\mu g} / \mathbf{m l})$ \\
\hline 1 & VMSA1 & 100 \\
2 & VMSA2 & 100 \\
3 & VMSA3 & 50 \\
4 & VMSA4 & 12.5 \\
5 & VMSA5 & 12.5 \\
6 & VMSA6 & 25 \\
7 & VMSA7 & 50 \\
8 & VMSA8 & 100 \\
9 & VMSA9 & 25 \\
10 & VMSA10 & 25 \\
11 & Ketoconazole & 12.5 \\
\hline
\end{tabular}

MIC: Minimum inhibitory concentrations

Hon. Shri Babanrao Pachpute Vichardhara Trust's, Group of Institutions College of Pharmacy for valuable support.

\section{REFERENCES}

1. Andriole VT. Effects of voriconazole on Candida glabrata in vitro. J Antimicrob Agents Chemother 1999;44:151-62.

2. Murray DK. Medical Microbiology. $2^{\text {nd }}$ ed. New York: Wiley; 1990. p. 299-323.

3. Petrikkos G, Skiada A. Recent advances in antifungal chemotherapy. Int J Antimicrob Agents 2007;30:108-17.

4. Georgopapadakou NH, Walsh TJ. Human mycoses: Drugs and targets for emerging pathogens. Science 1994;264:371-3.

5. Perfect JR. Effects of mycorrhizal fungi on in vitro nitrogen response of some Dutch indigenous orchid species Can J Bot 1995;73:1187-91.

6. Groll AH, Delucca AJ. Walsh TJ. Kinase-phosphatase competition regulates Bacillus subtilis development. Trend Microbiol 1998;6:117-24.

7. Perfect JR. Antimicrob agents chemother in vitro characterization of azoles resistance in Candida albicans 1996;40:1577-83.

8. Balkovec JM. Section review: Anti-infectives: Lipopeptide antifungal agents. Exp Opin Invest Drugs 1994;3:65-82.

9. Fox JJ, Watanabe KA, Bloch A. Candida endocarditis and the impact of antifungal treatment on the corrected QT interval: A case report. Prog Nucleic Acid Res Mol Biol 1966;7:251-313.

10. Bowman EJ, Siebers A, Altendorf K. Bafilomycins: A class of inhibitors of membrane ATP ases from microorganisms, animal cells, and plant cells. Proc Natl Acad Sci U S A 1988;85:7972-6.

11. Vincent TA. Risk of resistance related to antifungal use before admission in patients with community-acquired bacteraemia. J Antimicrob Chemother 1999;44:151.

12. Giulia M, Luisa, ME, Paola F, Silvia S, Angelo R, Lui C. Fungicidal activity of fluconazole against Candida albicans in a synthetic vaginasimulative medium. Bioorg Méd Chem 2004;12:5465

13. Xiao L, Madison V, Chau AS, Loebenberg D, McNicholas PM. Antimicrobial susceptibility and synergy studies of Stenotrophomonas maltophilia isolates from patients with cystic fibrosis. J Antimicrob Chemother 2004;48:568.

14. Hunt ML, Cox AJ, Ruffolo CG, Rajakumar K, Adler B. Characterisation of a Pasteurella multocida esterase gene which confers a hemolytic phenotype in Escherichia coli under anaerobic conditions. FEMS Microbiol Lett 2000;192:249-56.

15. Potts KT. The chemistry of 1, 2, 4-triazoles. Chem Rev 1961;61:87.

16. Heeres J, Meerpoel L, Lewi P. Conazoles. Molecules 2010;15:4129-88.

17. Bruch HA, Smith WO. Nitrofuryl heterocycles. iii. ${ }^{1} 3$-alkyl-5-(5-nitro2-furyl)-1, 2, 4-triazoles and intermediates. J Med Chem 1966;9:405.

18. Imperio D, Pirali T, Galli U, Pagliai F, Cafici L, Canonico PL, et al. Replacement of the lactone moiety on podophyllotoxin and steganacin analogues with a 1,5-disubstituted 1,2,3-triazole via rutheniumcatalyzed click chemistry. Bioorg Med Chem 2007;15:6748-57.

19. Kucukguzel I, Kucukguzel GS, Rollas S, et al. II Farmaco. Med Chem 2004;59:893.

20. Shivarama Holla B, Veerendra B, Shivananda MK, Poojary B. Synthesis characterization and anticancer activity studies on some mannich bases derived from 1,2,4-triazoles. Eur J Med Chem 2003;38:759-67.

21. Turan-Zitouni G, Sivaci M, Kiliç FS, Erol K. Synthesis of some triazolyl-antipyrine derivatives and investigation of analgesic activity. Eur J Med Chem 2001;36:685-9.

22. Hosur MS, Talwar R. Synthesis and antiinflammatory activity of 3-substituted-4-amino-5-mercapto-4(h)-1, 2, 4-triazole. Ind J Pharm Sci 1993;55:86.

23. Wade PC, Vogt BR, Kissick TP, Simpkins LM, Palmers DM. 1-Acyltriazoles as antiinflammatory agents. J Med Chem 1982;25:331.

24. Julino M, Stevens MF. Antitumour polycyclic acridines. Part 5.1 Synthesis of 7H-pyrido [4, 3, 2-kl] acridines with exploitable functionality in the pyridine ring. J Chem Soc Perkin Trans 1998;1:1677.

25. Passannanti A, Diana P, Barraja P, Lauria A, Montalbano A, Almerico AM. Antifungal compounds. Heterocycles 1998;48:1229.

26. Talwar MB, Laddi UV, Somannavar YS. Recent trends in antifungal agents and antifungal therapy. Indian J Heterocycl Chem 1995;4:297. 